\title{
Minimal switching of multiple input multilevel output DC-DC converter
}

\author{
Amer A. Chlaihawi, Ameen M. Al-Modaffer, Hur Jedi \\ Department of Electrical Engineering, University of Kufa, Najaf, Iraq
}



\section{INTRODUCTION}

The attraction of renewable energy resources has led to novel methods to utilize multiple clean resources, despite their low output voltage and power, production of an efficient and clean energy, such as photovoltaic, fuel cell and wind energy, can be utilized for simultaneouse delivery of continuous power to loads [1]-[3]. Researchers and scientists, during the last few decades, exert enthusiasm to acquire as much energy as possible from various resources of renewable energy to meet the enormous growth of energy demand for daily consumption. This effort lead to minimize a great deal of fossil energy reliance, which causes a lot of pollution, greenhouse gas emissions and other environmental damages[4]-[9].

The type of application plays an essential role in selecting the most appropriate topology, taking into account reliability, cost and flexibility. These features can be met by utilizing MIMLO system as it has several advantages, such as light weight, high efficiency, power density and small size. The rapid growth of demand on MIMLO with high voltage gain reflects the fact that it is quite obvious its advantages in many areas of power electronic applications [10]-[13]. The main idea behind employing a multiple input DC-DC convertor is to provide a certain voltage range from different levels of input voltages. This versatility of such system explains the high demand for DC-DC convertors in the field of power electronic; especially in the application field of renewable energy resources as it has low levels of voltage generation. In general, the simple construction of DC-DC convertor consists of inductor, capacitor and semiconductor switches. These 
components could be arranged in different topologies to get a wide variety of specification depend on kind of applications and type of sources' availability [14]-[15]. Due to that, many researchers have shown high interest and done great deal of researches on MIMLO DC-DC converters [16]-[19]. The parasitic parameters of DC-DC converters' components have an effect on the limitation of duty ratio. The duty ratio is almost around unity for high output voltage as it is seen in the step-up voltage of the non-isolated DC-DC boost converter topology[20]-[24].

The proposed MS-MIMLO DC-DC converter topology has a reduced number of switches of three inputs multilevel output (TIMLO) to facilitate the connection of available source among multiple sources of input [25]. The simulation results of the proposed topology have been carried out with comparison to existing of theoretical results of this study to validate the acquired results. The organization of this is as follow: Section 2 is dedicated for the analysis of the proposed topology and its operational modes. Section 3 presented the results of simulation and discussion of the merit of proposed model. Finally, Section 4 concluded summarization and conclusion.

\section{PROPOSED DC-DC CONVERTER TOPOLOGY}

The proposed MS-MIMLO DC-DC boost converter is shown in Figure 1. It consists of five switches, five diodes, an inductor, and two capacitors. In this study, it assumed that the semiconductor transistor and the diodes form ideal switches. The inductance of the proposed converter is high enough to provide low ripple input current. The value of capacitor $C_{1}$ is equal to the value of capacitor $C_{2}$. The schematic of the proposed topology has two parts. The first part is the generation of DC input voltage. It is utilized to generate a positive polarity voltage and provide the desired level of output voltage at a range of input DC sources. The proposed converter has three-unit cells, where each cell consists of a DC voltage source, a transistor as switch and a diode. The connected switch in series with the DC voltage source is considered as a voltage adder. The connected diode in parallel with the DC voltage source is considered as subtractor. Thus, the switches and diodes prevent the occurring of short circuit. Since the unit cell in the proposed topology is connected to each other in series and symmetric, the number of cells in the converter determine the output voltage level.

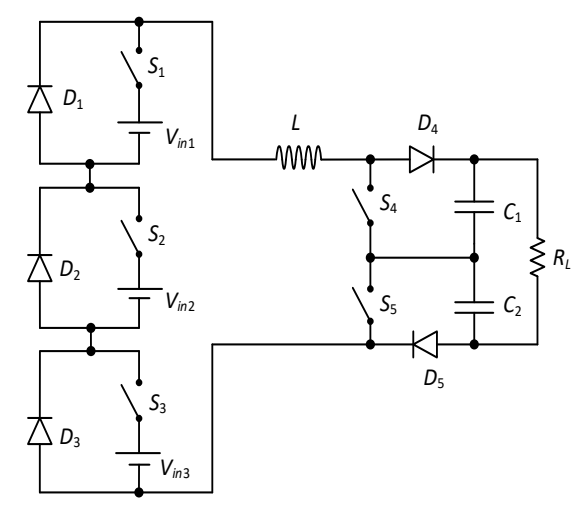

Figure 1. Proposed MSMIMLO DC-DC boost converter.

The second part of the proposed converter is a multilevel boost DC-DC converter. It comprises of an inductor $L$, two switches $\left(S_{4}, S_{5}\right)$, two diodes $\left(D_{4}, D_{5}\right)$ and two capacitors $\left(C_{1}, C_{2}\right)$. Since the converter operates under a resistive load, the resistor $R_{L}$ is utilized in the proposed circuit. It is desired that the converter operates at high switching frequency to provide the required output DC voltage. In this work, TIMLO DC-DC converter is analyzed as shown in Figure 2. As compare with the conventional boost DC-DC converter, the multi-level output boost converter (MLOBC) can achieve a wide range of step-up voltage in applications that require high voltage gain. The input voltage levels of the first part TIMLO of the converter operates in seven different states as shown in Table 1. In order to fully characterize the converter, the behavior of circuit is analyzed in each switching sub-interval to establish the equations of design and present the principle of operation. In general, the operation of the MLOBC converter is identical with the conventional boost converter in regard to the capacity of high power. A capacitor voltage balancing method is introduced to control the semiconductor devices of the converter. The output voltage $v_{O}$ is equal to the added voltage of the capacitors $\left(C_{1}, C_{2}\right)$. 


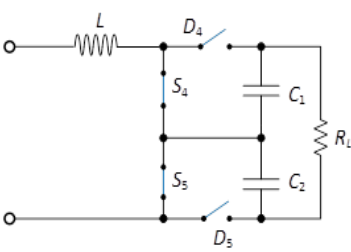

(a)

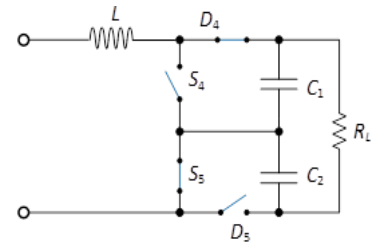

(b)

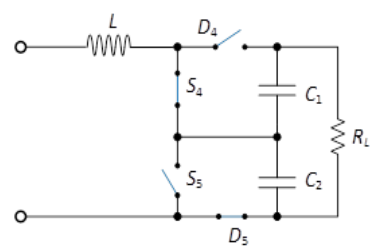

(c)

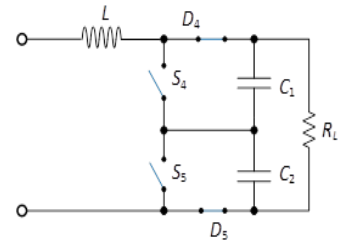

(d)

Figure 2. Equivalent circuits based on the states of operation mode

Table 1. Switches and diodes states

\begin{tabular}{cccccccc}
\hline State & $S_{1}$ & $D_{1}$ & $S_{2}$ & $D_{2}$ & $S_{3}$ & $D_{3}$ & Input voltage \\
\hline 1 & 1 & 0 & 0 & 1 & 0 & 1 & $V_{i n 1}$ \\
2 & 0 & 1 & 1 & 0 & 0 & 1 & $V_{i n 2}$ \\
3 & 0 & 1 & 0 & 1 & 1 & 0 & $V_{i n 3}$ \\
4 & 1 & 0 & 1 & 0 & 0 & 1 & $V_{i n 1}+V_{i n 2}$ \\
5 & 1 & 0 & 0 & 1 & 1 & 0 & $V_{i n 1}+V_{i n 3}$ \\
6 & 0 & 1 & 1 & 0 & 1 & 0 & $V_{i n 2}+V_{i n 3}$ \\
7 & 1 & 0 & 1 & 0 & 1 & 0 & $V_{i n 1}+V_{i n 2}+V_{i n 3}$ \\
\hline
\end{tabular}

Based on the module of the converter, there are four states for the switches $S_{4}$ and $S_{5}$ in their periodic switching. The state of switching can be described as $S_{4} \& S_{5}=\{11,10,01$, and 00$\}$, where logic 1 represents as "ON" state, while logic 0 represents as "OFF" state. Thus, the topology has four operation modes as shown in Table 2.

The voltage stress on the diodes D4, D5, S4, S5, C1 and C2 can be obtained according to the principal analysis of region one as described in Table 3. The current stress that flows in every component of the proposed converter is analyzed as described in Table 3 . The average of output current is $I_{O}$. In steadystate, the capacitors current average value is zero. The principle of balanced ampere-second is applied to the capacitors $C_{1}$ and $C_{2}$, respectively. It is assumed that the value of inductance is high enough and the current changes linearly.

Table 2. Operation modes

\begin{tabular}{cccccc}
\hline Mode operation & Switches Conditions & Diodes states & L & $C_{1}$ & $C_{2}$ \\
\hline Mode 1 & $S_{4}, S_{5}$ (on) & $D_{1}, D_{2}$ (revers-biased) & Charging & Discharging & Discharging \\
Mode 2 & $S_{4}$ (on), $S_{5}$ (off) & $D_{4}$ (forward-biased) $D_{5}$ (off) & Discharging & Discharging & Charging \\
Mode 3 & $S_{4}$ (off), $S_{5}$ (on) & $D_{4}$ (off) $D_{5}$ (forward-biased) & Discharging & Charging & Discharging \\
Mode 4 & $S_{4}, S_{5}$ (off) & $D_{1,} D_{2}$ (forward-biased) & Discharging & Discharging & Discharging \\
\hline
\end{tabular}

Table 3. Voltage and current stress parameters

\begin{tabular}{ccc}
\hline Stress & component & formula \\
\hline Voltage Stress & $D_{4}$ and $D_{5}$ & $V_{D 4}=V_{D 5}=\frac{1}{(1-d)} V_{i n}$ \\
& $C_{1}$ and $\mathrm{S} 5$ & $V_{S 4}=V_{S 5}=\frac{1}{(1-d)} V_{i n}$ \\
& $\mathrm{~L}$ & $V_{C 1}=V_{C 2}=\frac{1}{(1-d)} V_{i n}$ \\
Current Stress & $\mathrm{S} 4$ and $D_{5}$ & $I_{S 4}=\frac{2}{(1-d)} I_{O}$ \\
& $\mathrm{~S} 5$ and S4 & $I_{S 5}=\frac{2}{(1-d)} I_{D 4}=\frac{2}{(1-d)} I_{O}$ \\
\hline
\end{tabular}

\section{RESULTS AND ANALYSIS}

The effectiveness and validity of MS-MIMLO DC-DC module have been investigated in comparison with the non-isolated MIMLO DC-DC converter [25]. The comparison includes overshot, peak time, slow rate, rise time, peak to peak voltage and efficiency. The complete MS-MIMLO DC-DC module consist of five power switches, five diodes, the capacitors $C_{1}=C_{2}=60 \mu \mathrm{F}$, the resistive load $R_{L}$ is $550 \Omega$ and the inductor value is $L=1.13 \mathrm{mH}$. The MS-MIMLO DC-DC converter operates in continuous conduction 
mode and its switching frequency is $5 \mathrm{kHz}$. The simulated results at phase shift $0^{\circ}$ and $180^{\circ}$ between the control switches $S_{2}$ and $S_{3}$ were discussed. For $30 \mathrm{~V}$ of input voltage and $90 \%$ of duty cycle, the waveforms of voltage stress across the capacitors have an intermediate value near $262 \mathrm{~V}$ as illustrated in Figure 3 (a). On the other hand, when the input voltage is $100 \mathrm{~V}$ and the duty cycle is $81.3 \%$, the voltage stress waveforms across the capacitors have an intermediate value near $264 \mathrm{~V}$ as illustrated in Figure 3 (b). The voltage stress waveforms across the capacitors of the suggested module at $\left(V_{i n}=30 \mathrm{~V}, \mathrm{~d}=90 \%\right)$ and $\left(V_{\text {in }}=100 \mathrm{~V}, \mathrm{~d}=81.3 \%\right)$ are $234 \mathrm{~V}$ and $261 \mathrm{~V}$ respectively as observed from the simulation which is shown in Figure 4.

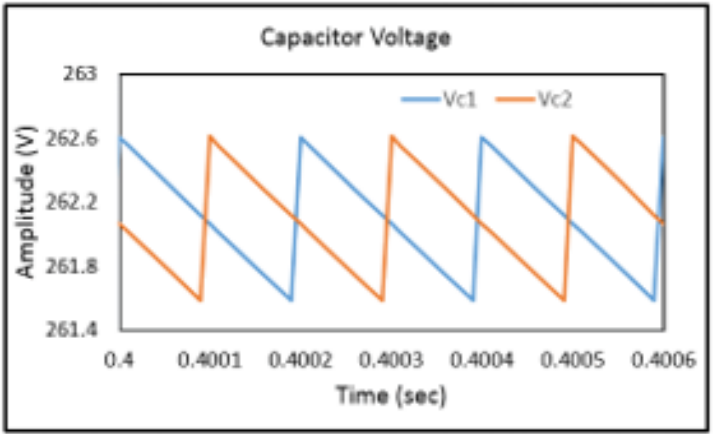

(a)

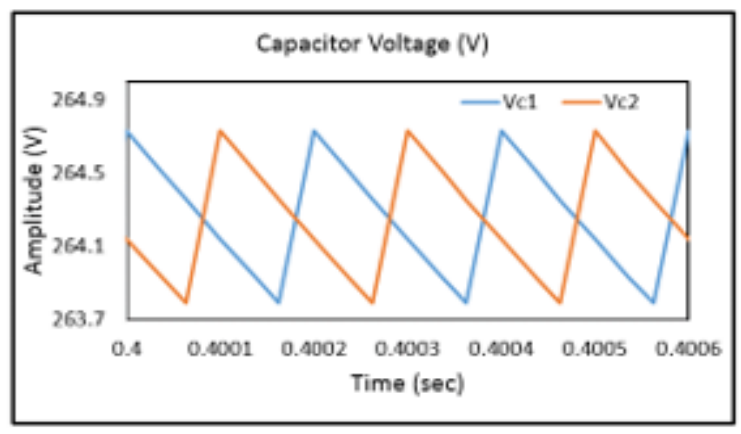

(b)

Figure 3. (a) capacitors voltage stress of MIMLO circuit when $V_{\text {in }}=30 \mathrm{~V}, \mathrm{~d}=90 \%$; (b) capacitors voltage stress of MIMLO circuit when $V_{\text {in }}=100, \mathrm{~d}=81.3 \%$

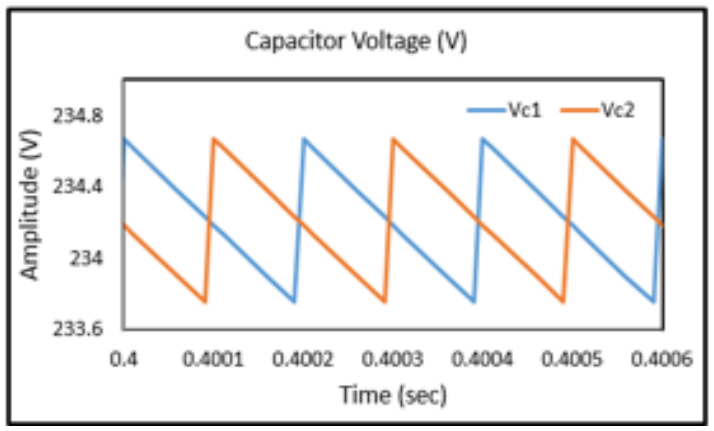

(a)

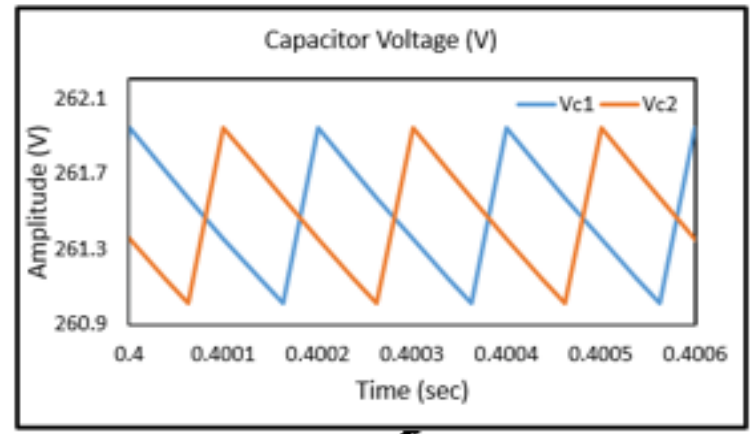

(b)

Figure 4. (a) capacitors voltage stress of the proposed MS-MIMLO circuit when $V_{\text {in }}=30 \mathrm{~V}, \mathrm{~d}=90 \%$; (b) capacitors voltage stress of the proposed MSMIMLO circuit when $V_{i n}=100 \mathrm{~V}, \mathrm{~d}=81.3 \%$

The shape of the voltage stress waveforms across $C_{l}$ and $C_{2}$ of both TIMLO and the proposed MSMIMLO DC-DC converter are matching each other and the switching frequency is out numbered the ripple frequency by twofold. The peak-to-peak voltage value on the capacitors of MS-MIMLO DC-DC converter is smaller than the peak-to-peak voltage value on the capacitors of TIMLO DC-DC converter due to biasing voltage of the diodes. The performance of the proposed MS-MIMLO DC-DC module is also verified in the simulation environment of the converter operation for a vast range of operation with variable output powers $(550 \mathrm{~W}, 1100 \mathrm{~W})$ and variable input-voltage $(30 \mathrm{~V}, 40 \mathrm{~V}, 60 \mathrm{~V}, 70 \mathrm{~V}, \& 100 \mathrm{~V})$. The results shown that the output voltage $\mathrm{VO}$ is the sum of both capacitor voltage $C_{1}$ and $C_{2}$. As can be seen in Table 4, the output voltage tracks the duty cycle, which proves decrease in the percentage of the output voltage amplitude with the increase of input voltage.

The dynamic behavior of the MS-MIMLO DC-DC converter has been explored through a transient analysis with constant output voltage $(525 \mathrm{~V})$. The output voltage response due to the change input voltage is shown in Figure 5.

Table 4. Input and output voltages with different duty cycles $\mathrm{d}_{\mathrm{T}}$ and $\mathrm{d}_{\mathrm{M}}$ of TIMLO and MS-MIMLO modules

\begin{tabular}{|c|c|c|c|c|c|c|c|c|c|c|c|c|}
\hline \multirow[b]{2}{*}{$V_{\text {in }}(\mathrm{V})$} & \multicolumn{12}{|c|}{$V_{O}(\mathrm{~V})$} \\
\hline & $\mathrm{d}_{\mathrm{T}}=0.6$ & $\mathrm{~d}_{\mathrm{M}}=0.6$ & $\Delta_{\mathrm{d} 0.6} \%$ & $\mathrm{~d}_{\mathrm{T}}=0.7$ & $\mathrm{~d}_{\mathrm{M}}=0.7$ & $\Delta_{\mathrm{d} 0.7} \%$ & $\mathrm{~d}_{\mathrm{T}}=0.8$ & $\mathrm{~d}_{\mathrm{M}}=0.8$ & $\Delta_{\mathrm{d} 0.8} \%$ & $\mathrm{~d}_{\mathrm{T}}=0.9$ & $\mathrm{~d}_{\mathrm{M}}=0.9$ & $\Delta_{\mathrm{d} 0.9} \%$ \\
\hline
\end{tabular}




\begin{tabular}{cccccccccccccc}
\hline & & & & & & & \\
\hline 30 & 147.5 & 139.3 & 5.56 & 196.5 & 185 & 5.85 & 288.9 & 270.2 & 6.47 & 525.1 & 468.9 & 10.70 \\
40 & 197.2 & 189.3 & 4.01 & 262.5 & 250.1 & 4.72 & 385.6 & 365.2 & 5.29 & 700.5 & 633.2 & 9.61 \\
60 & 296.5 & 291.5 & 1.69 & 394.4 & 385 & 2.38 & 579.1 & 561.9 & 2.97 & 1051 & 974 & 7.33 \\
70 & 346.1 & 340.9 & 1.50 & 460.4 & 450.2 & 2.22 & 675.8 & 656.8 & 2.81 & 1227 & 1138 & 7.25 \\
100 & 495 & 492.6 & 0.48 & 658.3 & 650.2 & 1.23 & 984.6 & 966.1 & 1.88 & 1753 & 1644 & 6.22 \\
\hline
\end{tabular}

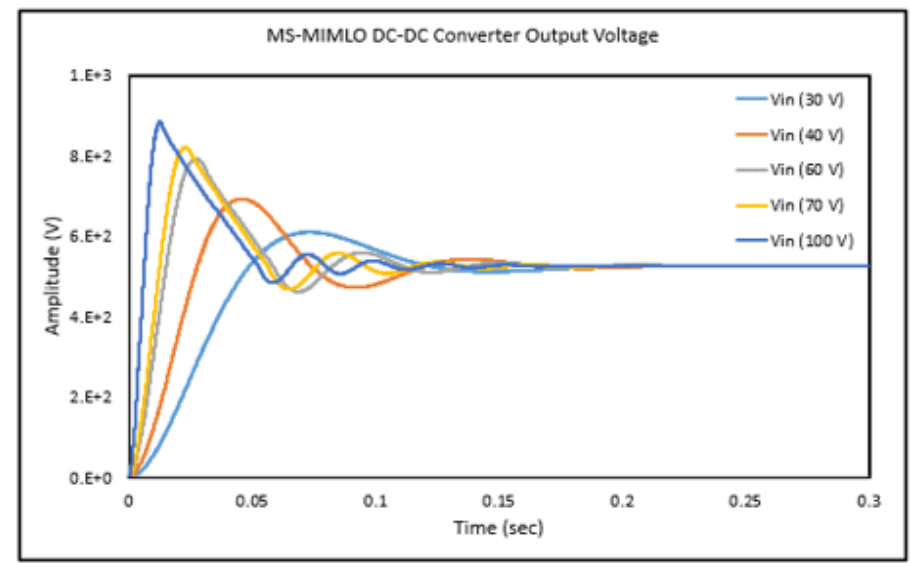

Figure 5. Input and output voltage of the proposed MS-MIMLO module.

The performance parameter of the response of MS-MIMLO DC-DC converter during transient process is shown in Table 5. The simulation results demonstrated an increase in the percentage of duty cycle, peak time, and rise time as well as decrease in the percentage of other parameters, such as slaw rate, peak to peak value and over shoot compared to TIMLO controller with low input voltage (Vin $=30 \mathrm{~V}$ ) [25]. The result of simulations verified the proposed converter effectiveness when input voltage increased (Vin $=100 \mathrm{~V})$.

Table 5. Performance of the MS-MIMLO converters

\begin{tabular}{cccccccc}
\hline$V_{\text {in }}(\mathrm{V})$ & $V_{O}(\mathrm{~V})$ & $t_{r}(\mathrm{msec})$ & Slew Rate & P-P Voltage $(\mathrm{V})$ & $t_{P}(\mathrm{msec})$ & Overshot & $\mathrm{d}$ \\
\hline 30 & 525 & 33.105 & 12.703 & 609.7 & 73 & $17.059 \%$ & 0.917 \\
40 & 525.3 & 18.709 & 22.212 & 692.6 & 46 & $32.667 \%$ & 0.87 \\
60 & 526.2 & 10.408 & 40.176 & 791.9 & 28 & $50.758 \%$ & 0.785 \\
70 & 525.3 & 8.586 & 48.414 & 821.4 & 24 & $57.937 \%$ & 0.764 \\
100 & 525.7 & 5.603 & 74.476 & 919.1 & 16 & $68.64 \%$ & 0.629 \\
\hline
\end{tabular}

Enough caution has been taken during simulation to ensure that the same simulation conditions are considered for comparing both modules as shown in Table 6. The analysis of the performance of the proposed MS-MIMLO converter in terms of efficiency has been verified.

Table 6. Comparison performance of the MS-MIMLO and TIMLO converters

\begin{tabular}{ccccccc}
\hline$V_{\text {in }}(\mathrm{V})$ & $\Delta t_{r} \%$ & ISlew Rate $\%$ & $\Delta \mathrm{P}-\mathrm{P}$ Voltage $\%$ & $\Delta t_{P} \%$ & $\Delta$ Overshot $\%$ & $\Delta \mathrm{d} \%$ \\
\hline 30 & 25.68 & -33.31 & -12.38 & 17.81 & -81.37 & 1.85 \\
40 & 13.38 & -15.84 & -9.05 & 8.70 & -35.31 & 1.38 \\
60 & 5.83 & -5.98 & -6.24 & 3.57 & -19.16 & 1.91 \\
70 & 5.52 & -5.70 & -5.25 & 4.17 & -13.63 & 0.52 \\
100 & 1.82 & -2.31 & 0.00 & 0.00 & -8.63 & 0.16 \\
\hline
\end{tabular}

The equivalent participation of switches with no extra switching losses satisfies the aim of the proposal design. Figure 6 represents the efficiency of the MS-MIMLO module with different duty cycles and input voltages. It can be observed from Figure 7 that the difference of presentage of efficiency is less than $0.8 \%$ between MS-MIMLO and TIMOL modules. Furthermore, the MS-MIMLO module provides favor of no overlap switch that may cause short circuit on the power sources. 


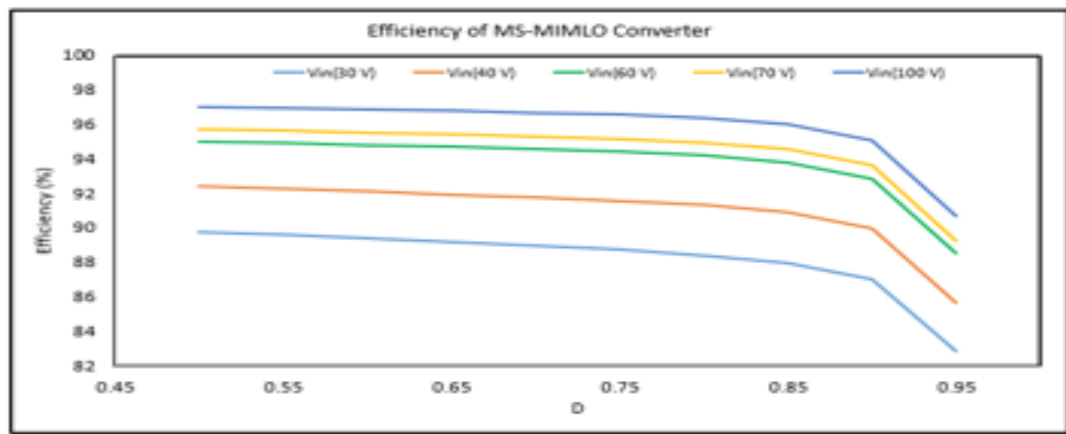

Figure 6. Efficiency with variable input voltages and different duty cycles

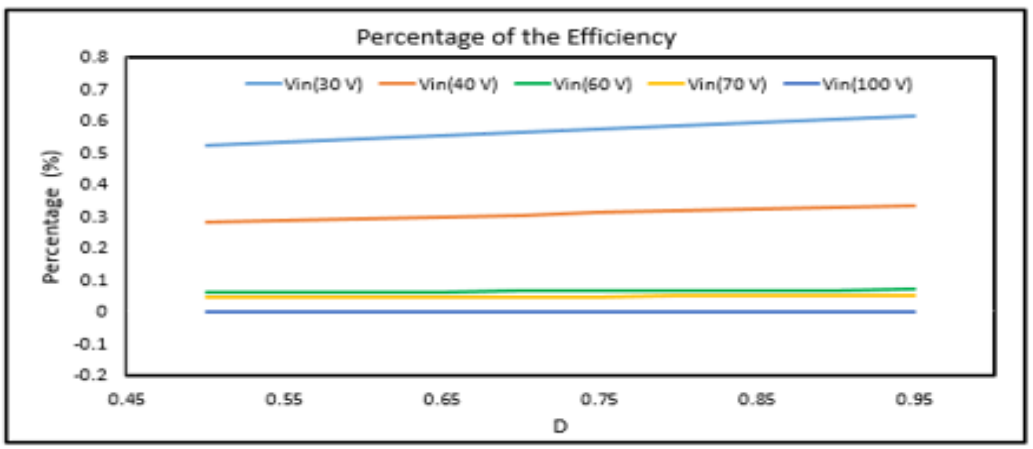

Figure 7. Percentage of efficiency with different duty cycles and fixed input voltages

\section{CONCLUSION}

This paper presented a detailed analysis on the operation and performance of MS-MIMLO DC-DC converter. The analysis was performed to confirm the concept and the principal operation of the converter with different modes of operation using MatLab/Simulink. The MS-MIMOL converter has been introduced the following advantages: (a) high static gain in terms of the input and output voltages, (b) low voltage stress across the switches $S_{4}$ and $S_{5}$, and (c) reduction of the reverse-biased voltage on the diodes $D_{4}$ and $D_{5}$. The results of simulation confirmed that the feature of voltage rating in the power switches was improved. It was shown that the converter has achieved high efficiency DC/DC convention with different input voltages suited for renewable energy applications. Thus, the proposed converter can easily operate on a variety of power conversion with minimal number of switching which showed significant benefits in terms of cost and fault reduction of circuit operation. It is expected that the suggested converter is widely suited for many applications, such as photovoltaic systems (PV), full cell (FC), and battery charging systems.

\section{REFERENCES}

[1] F. Sedaghati, "A Configuration of Double Input Z-Source DC-DC Converter for Standalone PV/Battery System Application,” J. Energy Manag. Technol., vol. 2, no. 3, pp. 60-69, 2018, DOI: 10.22109/JEMT.2018.121505.1069.

[2] M. Mohammadi, "Application of a New High Step-up Double-Input Converter in a Novel Module-IntegratedInverter Photovoltaic System," in IEEE Conferences (PEDSTC), 2015, DOI: 10.1109/PEDSTC.2015.7093249.

[3] A. A Chlaihaw, "Novel screen printed and flexible low frequency magneto-electric energy harvester," 2016 IEEE Sensors, Orlando, pp. 1-3, Nov. 2016, DOI: 10.1109/ICSENS.2016.7808947.

[4] E. C. and H. H. Sayan, "Different mathematical model for the chopper circuit," Teh. Glas. J., vol. 10, no. 1-2, pp. $13-15,2016$.

[5] T. Kousksou, "Energy storage:Applications and challenges," Sol. EnergyMaterials SolarCells, vol. 120, pp. 59-80, Jan. 2014, DOI: 10.1016/j.solmat.2013.08.015.

[6] A. Nahavandi, "A nonisolated multiinput multioutput DC-DC boost converter for electric vehicle applications," IEEE Transactions on Power Electronics, vol. 30, no. 4, pp. 1818-1835, Apr. 2015, DOI: 10.1109/TPEL.2014.2325830.

[7] M. R. Banaei, "Non-isolated multi-input-single-output DC/DC converter for photovoltaic power generation systems," IET Power Electron., vol. 7, no. 11, pp. 2806-2816, Nov. 2014, DOI: 10.1049/iet-pel.2013.0977. 
[8] T. Arunkumari, I. Jagadeesh, and V. Indragandhi, "Design and implementation of modified multilevel sepic converter for PV applications," Indonesian Journal of Electrical Engineering and Computer Science ,vol. 14, no. 3, pp. 1125-1133, Jun. 2019, DOI: 10.11591/ijeecs.v14.i3.pp1125-1133.

[9] F. Blaabjerg, Zhe Chen, and S.B. Kjaer, "Power electronics as efficient interface in dispersed power generation systems," IEEE Transactions on Power Electronics., vol. 19, no. 5, pp. 11184-1194, Sept. 2004, DOI: 10.1109/TPEL.2004.833453.

[10] D. B. Richardson, "Electric vehicles and the electric grid: A review of modeling approaches, Impacts, and renewable energy integration," Renew. Sustain. Energy Rev., vol. 19, pp. 247-254, Mar. 2013, DOI: 10.1016/j.rser.2012.11.042.

[11] H. Ye, "High step-up interleaved dc/dc converter with high efficiency," Energy Sources, Part A: Recovery, Utilization, and Environmental Effects, Jan. 2020, DOI: 10.1080/15567036.2020.1716111.

[12] A. Chlaihawi, "Genetic algorithm error criteria as applied to PID controller DC-DC buck converter parameters: an investigation," IOP Conference Series: Materials Science and Engineering, 2020.

[13] R. A. and M. R. B. F. Kardan, "A New Three Input DC/DC Converter for Hybrid PV/FC/Battery Applications," IEEE J. Emerg. Sel. Top. Power Electron., vol. 5, no. 4, pp. 1771-1778, Jul. 2017, DOI: 10.1109/JESTPE.2017.2731816.

[14] A. F. H. A. Gani, A. A. Bakar, A. Ponniran, M. Hussainar, and M. A. N. Amran, "Design and development of PWM switching for 5-level multiphase interleaved DC/DC boost converter," vol. 17, no. 1, pp. 131-140, 2020, DOI:10.11591/ijeecs.v17.i1.pp131-140.

[15] M. D. Siddique, "A New Switched Capacitor 7L Inverter with Triple Voltage Gain and Low Voltage Stress," IEEE Transactions on Circuits and Systems, vol. 67, no. 7, pp. 1294-1298, 2019.

[16] Y. Zhang, "Wide Input-Voltage Range Boost Three-Level DC-DC Converter With Quasi-Z Source for Fuel Cell Vehicles," IEEE Trans. Power Electron., vol. 32, no. 9, pp. 6728-6738, Sept. 2017, DOI: 10.1109/TPEL.2016.2625327.

[17] X. H. and C. Gong, "A High Gain Input-Parallel Output-Series DC/DC Converter With Dual Coupled Inductors," IEEE Trans. Power Electron., vol. 30, no. 3, pp. 1306-1317, Mar. 2015, DOI: 10.1109/TPEL.2014.2315613.

[18] A. Alzahrani, "Advanced topologies of high-voltage-gain DC-DC boost converters for renewable energy applications," Doctoral Dissertations, 2018.

[19] C. B. S. Rao, D. Kumar, "Grid Connected Distributed Generation System with High Voltage Gain Cascaded DCDC Converter Fed Asymmetric Multilevel Inverter Topology," International Journal of Electrical and Computer Engineering., vol. 8, no. 6, pp. 4047-4059, Dec. 2018, DOI: 10.11591/ijece.v8i6.pp4047-4059.

[20] C. A. Villarreal, "Modeling and control of an interleaved DC-DC multilevel boost converter," IEEE 18th Workshop on Control and Modeling for Power Electronics (COMPEL), Stanford, CA, 2017, pp. 1-6.

[21] K. Varesi, "Performance and design analysis of an improved non-isolated multiple input buck DC-DC converter," IET Power Electron., vol. 10, no. 9, pp. 1034-1045, Mar. 2017, DOI: 10.1049/iet-pel.2016.0750.

[22] Ziyu Xia, Benjamin L, Dobbins, Jan S. Rentmeister, and Jason T. Stauth, "State Space Analysis of Flying Capacitor Multilevel DC-DC Converters for Capacitor Voltage Estimation," 2019 IEEE Applied Power Electronics Conference and Exposition (APEC), Anaheim, CA, USA, 2019, pp. 50-57.

[23] T. Bascopé, "Three-state switching cell (3SSC)-based non-isolated DC-DC boost-type converter with balanced output voltage and wide voltage conversion range," IET Power Electron., vol. 11, no. 7, pp. 1217-1223, Jul. 2018, DOI: 10.1049/iet-pel.2017.0551.

[24] Xiaoquan Zhu and Bo Zhang, "High step-up quasi-Z-source DC-DC converters with single switched capacitor branch,” J. Mod. Power Syst. Clean Energy, vol. 5, no. 4, pp. 537-547, Jul. 2017, DOI: 10.1007/s40565-017-03041 .

[25] A. M. Al-modaffer, A. A. Chlaihawi, and H. A. Wahhab, "Non-isolated multiple input multilevel output DC-DC converter for hybrid power system," Indonesian Journal of Electrical Engineering and Computer Science, vol. 19, no. 2, pp. 635-643, Aug. 2020, DOI: 10.11591/ijeecs.v19.i2.pp635-643. 